\title{
Effect of Variation of Lubricant Concentration (Magnesium Stearate) on The Physical Quality of Metoclopramid HCl Tablets With Direct Printing Method
}

\author{
(Pengaruh Variasi Konsentrasi Magnesium Stearat Terhadap Mutu \\ Fisik Tablet Kunyah Metoklopramid $\mathrm{HCl}$ Metode Cetak Langsung)
}

\section{Valiandri Puspadina1, Deny Budi Legowo', Erna Fitriany ${ }^{1 *}$, Andri Priyoherianto1, Winda Damayanti ${ }^{1}$}

${ }^{1}$ Akademi Farmasi Mitra Sehat Mandiri Sidoarjo

*E-mail: ernafitriany9@gmail.com

\section{Article Info:}

Received: 14 April 2021

in revised form: 18 Mei 2021

Accepted: 27 Mei 2021

Available Online: 27 Mei 2021

\section{Keywords:}

Metoclopramie $\mathrm{HCl}$

Chewable Tablet

Mg-stearate

Corresponding Author:

Erna Fitriany

Akademi Farmasi Mitra Sehat

Mandiri Sidoarjo

E-mail:

ernafitriany9@gmail.com

\begin{abstract}
Metoclopramide $\mathrm{HCl}$ is used to relieve nausea and vomiting. Market availability in the form of tablets, syrup and injection. The most preferred drug use by patients is oral medication because of its ease of use. Chewable tablets are a new product as an alternative for treatment in pediatric and adult patients who have difficulty swallowing drugs. Objectives: This study aims to formulate the chewable tablet preparations of metoclopramide $\mathrm{HCl}$ using variations in lubricant concentrations. The variations of magnesium stearate with concentrations of $1 \%, 2 \%$, and $3 \%$ using the direct printing method made to obtain a better physical quality test including organoleptics, weight uniformity, uniformity of size, tablet hardness, tablet brittleness, tablet crush time, uniformity of content. The results of the physical quality test were statistically analyzed using one way ANOVA to determine the effect of variations in the concentration of lubricants on the characteristics of chewable tablets. The results showed that variations in the concentration of magnesium stearate lubricant in the manufacture of metoclopramide $\mathrm{HCl}$ chewable tablets had an effect on the physical quality of metoclopramide $\mathrm{HCl}$ chewable tablets. Conclusions: The concentration of magnesium stearate which produces metoclopramide $\mathrm{HCl}$ chewable tablets with good physical properties is $2 \%$.
\end{abstract}

Copyright $\odot 2021$ IJPE-UNG

This open access article is distributed under a Creative Commons Attribution (CC-BY-NC-SA) 4.0 International license. 


\section{ABSTRAK}

Metoklopramid $\mathrm{HCl}$ digunakan untuk meredakan mual dan muntah. Ketersediaan di pasaran dalam bentuk tablet, sirup dan injeksi. Penggunaan obat yang paling disukai pasien adalah obat oral karena kemudahannya dalam penggunaan. Tablet kunyah merupakan produk baru sebagai alternatif untuk pengobatan pada pasien anak-anak dan dewasa yang mengalami kesulitan dalam menelan obat. Penelitian ini bertujuan untuk memformulasi sediaan tablet kunyah metoklopramid $\mathrm{HCl}$ menggunakan variasi konsentrasi lubrikan yaitu magnesium stearat dengan konsentrasi 1\%, 2\%, dan 3\% menggunakan metode cetak langsung dibuat untuk mendapatkan uji mutu fisik yang lebih baik meliputi organoleptik, keseragaman bobot, keseragaman ukuran, kekerasan tablet, kerapuhan tablet, waktu hancur tablet, keseragaman kandungan. Hasil uji mutu fisik dianalisis secara statistic menggunakan one way ANOVA untuk mengetahui pengaruh variasi konsentrasi lubrikan terhadap karakteristik tablet kunyah. Hasil penelitian menunjukkan bahwa variasi konsentrasi lubrikan magnesium stearat pada pembuatan tablet kunyah metoklopramid $\mathrm{HCl}$ berpengaruh terhadap mutu fisik tablet kunyah metoklopramid $\mathrm{HCl}$. Konsentrasi magnesium stearat yang menghasilkan tablet kunyah metoklopramid $\mathrm{HCl}$ dengan sifat fisik baik adalah $2 \%$.

Kata Kunci: Metoklopramid $\mathrm{HCl}$; tablet kunyah; magnesium stearat

\section{Pendahuluan}

Metoklopramid $\mathrm{HCl}$ merupakan derivat aminoklorbenzamida yang berkhasiat sebagai anti emetis yang kuat berdasarkan blokade dari reseptor dopamin di CTZ. Disamping itu zat ini juga memperkuat pergerakan dan pengosongan lambung (propulsivum)[1]. Metoklopramid $\mathrm{HCl}$ menjadi salah satu obat yang paling banyak diberikan untuk gangguan motilitas gastrointestinal karena sifat prokinetiknya. Saat ini sediaan yang mengandung metoklopramid $\mathrm{HCl}$ yang telah beredar di pasar berada dalam bentuk sediaan tablet, sirup dan injeksi[2]. Pemberian secara oral merupakan rute yang paling populer karena kemudahan penggunaan, menghindari rasa sakit, dan yang paling penting adalah berkaitan dengan kepatuhan pasien. Tablet oral sulit untuk ditelan bagi penderita disfagia, mual atau muntah, selain itu pada pasien dengan gastroparesis berat penyerapan obat oral mungkin terhambat atau tertunda secara signifikan[2].

Beberapa pasien dewasa dan anak-anak kesusahan dalam menelan sediaan tablet konvensional. Dari permasalahan tersebut, beberapa obat diformulasikan sebagai tablet kunyah[3]. Karakteristik tablet kunyah apabila dikunyah akan membentuk massa yang halus, mempunyai rasa yang enak dan tidak meninggalkan rasa pahit ${ }^{[4]}$. Keuntungan tablet kunyah jika dibandingkan sediaan padat oral lainnya meliputi ketersediaan hayati yang lebih baik, melewati proses disintregasi dan dapat menghasilkan peningkatan disolusi, kenyamanan pasien dengan meniadakan kebutuhan air minum untuk menelan, dapat digunakan sebagai pengganti bentuk sediaan cair jika diperlukan kerja obat (onset) yang cepat, meningkatkan penerimaan pasien (terutama anak - anak) karena cita rasa yang menyenangkan dan memiliki keunikan produk dari sudut pandang pemasaran[5]. Selain itu terdapat keterbatasan penggunaan tablet kunyah antara lain rasa zat aktif yang buruk dan zat aktif yang mempunyai tingkat konsentrasi dosis yang sangat tinggi memberikan kendala signifikan untuk diatasi oleh formulator ${ }^{[5]}$.

Proses pembuatan tablet secara granulasi basah, granulasi kering, atau kempa langsung dapat diterapkan pada tablet kunyah seperti pada tipe tablet lainnya. Umumnya tabet kunyah menggunakan manitol, sorbitol, atau sukrosa sebagai bahan pengisi ${ }^{[5]}$. Pembuatan tablet kunyah biasanya digunakan metode cetak langsung karena 
ketersediaan bahan tambahan untuk cetak langsung seperti mannitol[3]. Metode cetak langsung merupakan metode yang paling sering dipilih karena waktu yang singkat, efektif, dan tidak terlalu banyak langkah-langkah yang harus dilakukan[6]. Komponenkomponen dalam memformulasi tablet kempa terdiri atas zat aktif, bahan pengisi, bahan pengikat, desintegran, dan lubrikan, dapat juga mengandung bahan pewarna, bahan pengaroma dan bahan pemanis[7]. Memilih bahan tambahan yang sesuai untuk mendapatkan fungsi yang spesifik pada formulasi tablet seperti lubrikan bisa menjadi parameter kritis untuk mendapatkan produk yang dapat diterima ${ }^{[8]}$. Lubrikan berfungsi mengurangi gesekan selama proses pengempaan tablet dan juga untuk mencegah massa tablet melekat pada cetakan[5].

Jenis lubrikan yang lazim digunakan adalah logam stearat, stearowet $C$, asam stearat, talk, amilum, natrium benzoat dan natrium klorida, natrium dan magnesium lauril sulfat, polietilen glikol, dan gliseril behanat ${ }^{[5]}$. Logam stearat merupakan lubrikan yang paling efisien dan lazim digunakan. Pada umumnya lubrikan ini tidak reaktif. Logam stearat yang paling luas digunakan adalah magnesium[5]. Menurut handbook of pharmaceutical of excipients konsentrasi magnesium stearat yang digunakan adalah $0,25 \%$ hingga 5,0\%. Pemilihan konsentrasi dari magnesium stearat dapat menyebabkan serbuk yang hidrofobik ${ }^{[9]}$. Sifat hidrofobik dari magnesium stearat akan membuat lapisan film pada partikel bahan padat sehingga dapat mengurangi gesekan antar partikel dan memudahkan partikel tersebut mengalir. Selain itu adanya sifat hidrofobik dapat menghambat penetrasi air dengan membentuk lapisan film sehingga dapat memberikan pengaruh negatif terhadap waktu hancur tablet[3]. Magnesium stearat memungkinkan meningkatkan kerapuhan tablet[9].

Berdasarkan alasan - alasan diatas, maka perlu dilakukan penelitian lebih lanjut mengenai pengaruh konsentrasi magnesium stearat sebagai lubrikan terhadap sifat fisik tablet kunyah metoklopramid $\mathrm{HCl}$ dengan menggunakan metode cetak langsung. Variasi konsentrasi magnesium stearat dimungkinkan dapat mempengaruhi sifat fisik tablet seperti kekerasan tablet, kerapuhan tablet dan waktu hancur tablet.

\section{Metode}

Alat yang digunakan dalam penelitian ini adalah Timbangan digital, v-mixer, gelas ukur, kaca arloji, pipet, mikro pipet, beaker glass, ayakan mesh 20, corong kaca, single punch, jangka sorong, hardness tester, friability tester, disintegran tester, spektrofotometri UV-Vis. Bahan yang digunakan dalam penelitian ini adalah Metoklopramid $\mathrm{HCl}$, PVP K30, magnesium stearat, talk, aspartam, mannitol, kalium dihidrogen fosfat, natrium hidroksida.

Tabel 1. Formulasi Tablet Kunyah Metoklopramid $\mathrm{HCl}$

\begin{tabular}{ccccc}
\hline Bahan & Fungsi & F I & F II & F III \\
\hline Metoklopramid HCl & Zat aktif & $5 \mathrm{mg}$ & $5 \mathrm{mg}$ & $5 \mathrm{mg}$ \\
Magnesium stearat & Lubrikan & $1 \%$ & $2 \%$ & $3 \%$ \\
PVP K30 & Pengikat & $4 \%$ & $4 \%$ & $4 \%$ \\
Talk & Glidan & $5 \%$ & $5 \%$ & $5 \%$ \\
Aspartam & pemanis & $1 \%$ & $1 \%$ & $1 \%$ \\
Mannitol & Pengisi & qs & qs & qs \\
\hline
\end{tabular}

Uji yang dilakukan dalam penelitian ini meliputi uji evaluasi sediaan tablet dan yang meliputi: uji sifat alir, uji sudut diam, dan uji kompresibilitas. Dalam penelitian ini juga dilakukan uji organoleptis sediaan tablet yang meliputi uji keseragaman bobot, uji kerapuhan, uji kekerasan, dan uji waktu hancur. 
2.1 Evaluasi mutu granul

2.1.1 Uji Sifat Alir

Uji sifat alir dilakukan dengan menimbang $100 \mathrm{~g}$ granul, lalu di alirkan melalui corong dengan jarak corong dengan dasar adalah $10 \mathrm{~cm}$. Batas alir maksimum adalah 10 detik [11].

\subsubsection{Sudut diam}

Pengujian dilakukan dengan menuangkan melalui corong dengan ukuran tertentu, diletakan pada ketinggian tertentu dan diletakan diatas bidang datar. Luas dan tinggi gundukan kemudian diukur[11].

\subsubsection{Kompresibilitas}

Kompresibilitas dapat dilihat dari harga indeks Carr yang sangat bergantung pada kerapatan nyata maupun kerapatan mampat dari granul yaitu dengan cara kerapatan mampat dikurangi kerapatan nyata, lalu dibagi dengan kerapatan mampat ${ }^{[11]}$.

\subsection{Uji mutu fisik}

2.2.1 Uji organoleptis

Penampilan fisik tablet yang diamati meliputi tidak ada capping, cracking, picking dan karakteristik lain yang menandakan adanya kerusakan tablet[11].

\subsubsection{Keseragaman bobot}

Keseragaman bobot dapat menjadi indikator awal keseragaman kandungan/kadar zat aktif. Uji keseragaman bobot tablet dilakukan dengan menimbang 20 tablet dan dihitung rata-rata tiap tabletnya, tidak boleh ada lebih dari dua tablet yang bobotnya lebih dari angka yang tercantum dalam kolom A, dan hasil timbang tablet tidak boleh menyimpang dari tabel B. Berikut adalah tabel persyaratan keseragaman bobot tablet [11].

\subsubsection{Uji kerapuhan}

Uji kerapuhan tablet dilakukan dengan menggunakan alat friability tester dengan cara menimbang 20 tablet, lalu dicatat bobot sebelum di masukkan alat. Setelah itu di masukan ke dalam alat dan mesin jalankan dengan kecepatan 25 rpm selama 4 menit kemudian ditimbang bobot tablet setelah di lakukan pengujian. Syarat kerapuhan tablet yang dikehendaki adalah sebesar $1 \%$ atau kurang untuk tablet konvensional, sedangkan untuk tablet kunyah (karena kekerasan yang lebih rendah), nilai friabilitas sampai $4 \%$ dapat diterima [11].

\subsubsection{Uji waktu hancur}

Uji waktu hancur dilakukan menggunakan alat desintegran dengan cara memasukkan 6 tablet kedalam keranjang yang tersedia. Lalu keranjang di naik turunkan ke dalam cairan pelarut hingga hancur. Tablet dinyatakan memiliki waktu hancur yang baik apabila tablet tersebut hancur dalam waktu kurang dari 15 menit dan tidak lebih dari 30 menit untuk tablet salut gula dan salut selaput ${ }^{[11]}$. 


\section{Hasil dan Pembahasan}

\subsection{Uji Evaluasi Tablet}

Tablet kunyah metoklopramid $\mathrm{HCl}$ dibuat menggunakan metode cetak langsung dengan tiga macam formula (Tabel 1). Sebelum melakukan penimbangan, masingmasing bahan ditimbang terlebih dahulu sesuai dengan komposisi yang tertera pada Tabel 1. Uji evaluasi granul dilakukan untuk mengetahui bahwa granul yang sudah terbentuk telah memenuhi persyaratan atau belum. Uji evaluasi granul uji waktu alir, uji sudut diam dan uji kompresibilitas

\subsubsection{Uji Sifat Alir}

Uji sifat alir granul memiliki persyaratan dengan menimbang 50 gram granul mengalir dalam waktu kurang dari atau sama dengan 5 detik.

Tabel 1. Formulasi tablet kunyah metoklopramid $\mathrm{HCl}$

\begin{tabular}{llllllll}
\hline No & \multicolumn{6}{c}{ Penambahan lubrikan } \\
& \multicolumn{5}{c}{ Rata- rata sebelum } & \multicolumn{4}{c}{ Rata- rata sesudah } \\
& $\mathrm{W}(\mathrm{g})$ & $\mathrm{t}($ detik $)$ & $\mathrm{w} / \mathrm{t}$ & $\mathrm{W}(\mathrm{g})$ & $\mathrm{t}($ detik) & $\mathrm{w} / \mathrm{t}$ & $\mathrm{Sd}$ \\
\cline { 2 - 8 } FI & 50 & - & Tidak mengalir & 50 & 8,49 & 5,88 & 0,16 \\
FII & 50 & - & Tidak mengalir & 50 & 6,08 & 8,29 & 0,95 \\
FIII & 50 & - & Tidak mengalir & 50 & 4,66 & 10,78 & 0,89 \\
\hline
\end{tabular}

Uji sifat alir pada granul memiliki persyaratan dengan menimbang 50 gram granul mengalir dalam waktu kurang dari atau sama dengan 5 detik. Berdasarkan data pada tabel I, maka formulasi I dan II tidak memenuhi persyaratan, formulasi III memenuhi persyaratan. Berdasarkan uji one way Anova, didapatkan nilai signifikan 0,001 ( $p<0,05)$ yang artinya terdapat perbedaan yang signifikan pada uji sifat alir granul antar formula tablet kunyah metoklopramid $\mathrm{HCl}$. Waktu alir yang paling cepat adalah pada formulasi 3 (magnesium stearat 3\%), disusul formulasi 2 (magnesium stearat $2 \%$ ) dan yang terakhir formulasi I (magnesium stearat 1\%). Dari data tersebut bahwa formulasi III dengan konsentrasi magnesium stearat 3\% mempunyai sifat alir yang lebih baik dibandingkan dengan formulasi I dan formulasi II, hal ini disebabkan semakin tinggi konsentrasi magnesium stearat semakin tinggi pula kemampuannya mengatasi melekatnya antar partikel sehingga mengurangi gesekan antar partikel dan menyebabkan kecepatan alir granul menjadi baik[13].

\subsubsection{Uji Sudut Diam}

Pengujian sudut diam digunakan untuk mengevaluasi sifat alir. Rumus yang digunakan untuk menghitung sudut diam11:

Tabel 2. Uji sudut diam

$$
\text { Tga }=(\text { tinggi kerucut }(\mathrm{h})) /(\text { jari-jari kerucut }(\mathrm{r}))
$$

\begin{tabular}{ccccc}
\hline Uji Sudut Diam (0) & FI & FII & FIII & Standart \\
\hline Rata-rata + SD & $36,47 \pm 1,08$ & $26,38 \pm 0,75$ & $23,71 \pm 1,48$ & $20-40$
\end{tabular}

Berdasarkan uji one way Anova, didapatkan nilai signifikan 0,000 $(\mathrm{p}<0,05)$ yang artinya terdapat perbedaan yang signifikan pada uji sudut diam antar formula tablet kunyah metoklopramid $\mathrm{HCl}$. Dari data tersebut menunjukkan bahwa penggunaan magnesium stearat dengan konsentrasi yang berbeda menghasilkan sudut diam granul yang berbeda dimana penggunaan magnesium stearat dengan konsentrasi 3\% memiliki sudut diam yang paling kecil. Sudut diam berbanding lurus dengan waktu alir, semakin 
kecil atau cepat waktu alir maka sudut diam yang dibentuk suatu granul akan semakin kecil. Semakin kecil sudut diam yang terbentuk, menggambarkan granul mempunyai kohesifitas yang kecil sehingga kemampuan alirannya menjadi semakin baik dan semakin besar sudut istirahat yang terbentuk akan mempersulit granul untuk mengalir dari hopper ke ruang cetakan tablet sehingga sifat alir dari granul menjadi buruk[5]

\subsubsection{Uji Kompresibilitas}

Penentuan kompresibilitas digunakan untuk menghasilkan tablet yang baik. Kompresibilitas dapat dilihat dari harga indeks Carr yang sangat bergantung pada kerapatan nyata maupun kerapatan mampat dari granul yaitu dengan cara kerapatan mampat dikurangi kerapatan nyata, lalu dibagi dengan kerapatan mampat11.

Kompresibilitas $=($ kerapatan mampat-kerapatan nyata $) /($ kerapatan mampat $) \times 100 \%$

Tabel 3. Uji Kompesibilitas

\begin{tabular}{lcccc}
\hline Uji Kompresibilitas (\%) & FI & FII & FIII & Standart \\
\hline Rata-rata + SD & $46,67 \pm 2,88$ & $36,67 \pm 2,88$ & $20,008 \pm 5,00$ & $<20$ \\
\hline
\end{tabular}

Persyaratan pada uji kompresibilitas yaitu sebesar $<20 \%$, berdasarkan hasil peelitian yang tertera pada tabel 3, maka hanya F III yang memenuhi persyaraatan. Berdasarkan uji one way Anova didapatkan nilai signifikan $0,000(\mathrm{p}<0,05)$ yang artinya terdapat perbedaan yang signifikan pada uji kompresibilitas antar formula tablet kunyah metoklopramid $\mathrm{HCl}$. Pada FIII yang menggunakan konsentrasi magnesium stearat sebesar 3\% mempunyai nilai kompresibilitas yang paling kecil diantara formula lainnya, hal ini menunjukkan bahwa konsentrasi magnesium stearat mempengaruhi kompresibilitas granul. Semakin kecil nilai kompresibilitas, maka sifat alir dari granul akan semakin baik14. Dari ketiga evaluasi mutu granul tersebut dapat disimpulkan bahwa semakin tinggi konsentrasi magnesium stearat semakin mempercepat sifat alir granul. Perbedaan konsentrasi magnesium stearat dapat berpengaruh terhadap sifat alir granul[9].

\subsection{Uji Organoleptis}

Uji organoleptis yang dilakukan dalam penelitian ini antara lain: uji keseragaman bobot, uji kerapuhan, uji kekerasan, uji waktu hancur, dan uji keseragaman kandungan.

\subsubsection{Uji Keseragaman Bobot}

Uji keseragaman bobot memiliki persyaratan tidak boleh lebih dari 2 tablet yang bobotnya lebih dari 5\% (665mg - 735mg) dan tidak 1 tablet pun yang bobotnya lebih dari 10\% (630mg - 770mg) dari bobot tablet ${ }^{[12]}$.

Tabel 4. Uji Keseragaman bobot

\begin{tabular}{ccccc}
\hline Uji Keseragaman bobot $(\mathbf{g})$ & FI & FII & FIII & Standart \\
\hline Rata-rata + SD & $0,687 \pm 0,012$ & $0,693 \pm 0,014$ & $0,678 \pm 0,007$ & $0,630-0,770$ \\
\hline
\end{tabular}

Uji keseragaman bobot memiliki persyaratan tidak boleh lebih dari 2 tablet yang bobotnya lebih dari 5\% (665mg - 735mg) dan tidak 1 tablet pun yang bobotnya lebih dari 10\% (630mg - 770mg) dari bobot tablet ${ }^{[14]}$. Hasil yang diperoleh pada uji keseragaman bobot sudah memenuhi persyaratan dengan bobot rata-rata tiap formulasi antara 666mg - 714mg. Hasil uji statistik one way Anova didapatkan nilai signifikan $0,001(\mathrm{p}<0,05)$ yang artinya terdapat perbedaan yang signifikan pada uji keseragaman bobot antar formula tablet kunyah metoklopramid $\mathrm{HCl}$. Keseragaman bobot dipengaruhi oleh sifat alir. Sifat alir yang baik menyebabkan volume bahan masuk ke 
dalam ruang kompresi akan seragam sehingga variasi bobot tablet yang dihasilkan tidak terlalu besar.

\subsubsection{Uji Kerapuhan}

Tablet kunyah memiliki nilai kerapuahan sampai $4 \%$ masih dapat diterima karena tablet kunyah memiliki nilai kekerasan yang rendah sehingga dapat menghasilkan tablet dengan tingkat kerapuhan yang tinggi[5].

Tabel 6. Uji kerapuhan

\begin{tabular}{ccccc}
\hline Uji kerapuhan (\%) & FI & FII & FIII & Standart \\
\hline Rata-rata + SD & $7,01 \pm 1,69$ & $9,05 \pm 0,52$ & $7,01 \pm 1,69$ & $9,05 \pm 0,52$ \\
\hline
\end{tabular}

Hasil uji statistik kruskal wallis didapatkan nilai signifikan $0,027(\mathrm{p}<0,05)$ yang artinya terdapat perbedaan yang signifikan pada uji kerapuhan antar formula tablet kunyah metoklopramid $\mathrm{HCl}$. Setiap formulasi tidak memenuhi persyaratan kerapuhan tablet kunyah yaitu diatas $4 \%$. Nilai kerapuhan yang tinggi dapat terjadi karena ikatan partikel pada bagian tepi tablet kurang kuat, sehingga adanya gesekan pada bada bagian tersebut menyebabkan partikel lepas dengan mudah[15]. Kerapuhan tablet berguna untuk mengetahui ketahanan tablet terhadap guncangan yang terjadi selama proses pembuatan, pengemasan, dan pendistribusian.

\subsubsection{Uji Kekerasan}

Hasil uji kekerasan disajikan dalam tabel berikut.

Tabel 7. Uji kekerasan

\begin{tabular}{ccccc}
\hline Uji kerapuhan (\%) & FI & FII & FIII & Standart \\
\hline Rata-rata + SD & $2,55 \pm 0,49$ & $3 \pm 0,33$ & $3,75 \pm 0,42$ & 3 \\
\hline
\end{tabular}

Persyaratan kekerasan pada tablet kunyah adalah $3 \mathrm{kp}{ }^{[10]}$. Berdasakan data pada tabel 7, maka hanya FII yang memenuhi persyaratan kekerasan tablet kunyah. Adanya perbedaan konsentrasi dari magnesium stearat dapat mempengaruhi kekerasan tablet ${ }^{[10]}$ .Pada data tersebut didapatkan hasil bahwa semakin tinggi konsentrasi magnesium stearat mengakibatkan nilai kekerasan semakin meningkat. Hal ini disebabkan karena adanya perbedaan kompresibilitas. Kompresibilitas granul yang semakin rendah mengakibatkan granul akan semakin kompak ketika dicetak menjadi tablet dan nilai kekerasan tablet akan semakin tinggi[13].

\subsubsection{Uji Waktu Hancur}

Uji waktu hancur menurut Farmakope edisi V, waktu hancur untuk tablet tidak bersalut adalah tidak lebih dari 15 menit.

Tabel 8. Uji waktu hancur

\begin{tabular}{ccccc}
\hline Uji kerapuhan (\%) & FI & FII & FIII & Standart \\
\hline Rata-rata + SD & $7,52 \pm 0,02$ & $9,43 \pm 0,01$ & $16,56 \pm 0,01$ & 15 \\
\hline
\end{tabular}

Uji waktu hancur menurut Farmakope edisi V, waktu hancur untuk tablet tidak bersalut adalah tidak lebih dari 15 menit. Berdasarkan hasil yang tertera pada tabel 8, maka FI dan FII memenuhi persyaratan, sedangkan FIII tidak memenuhi persyaratan. Hal tersebut dikarenakan tabet kuyah pada FIII memiliki konsentrasi Mg- stearat sebesar $3 \%$, sehingga tidak mampu menyerap air dalam jumlah yang cukup untuk menimbulkan aksi melawan bahan pengikat dan tekanan kompresi sehingga waktu hancur tablet menjadi besar dan kekerasan tablet yang tinggi dapat mempersulit 
masuknya air kedalam tablet dan menyebabkan semakin lama waktu hancur tablet ${ }^{[15]}$. Selain itu, tingginya Mg-stearat dapat empengaruhi sifat hidrofobik, sehingga akan menghambat penetrasi air dengan membentuk lapisan film sehingga dapat memberikan pengaruh negatif terhadap waktu hancur tablet[15].

\section{Kesimpulan}

Berdasarkan penelitian ini, maka dapat disimpulkan bahwa ada pengaruh konsentrasi Mg- stearat dengan konsentrasi 1\%, 2\%,3\% sebagai lubrikan terhadap mutu fisik tablet kunyah metoklopramid $\mathrm{HCl}$. Hasil uji mutu fisik yang optimal ditunjukkan pada konsentrasi Mg- stearat sebesar 2\%.

\section{Referensi}

[1] Tjay, Tan Hoan dan Kirana Rahardja. 2007. Obat-Obat Penting Khasiat, Penggunaan dan Efek-Efek Sampingnya, Edisi Keenam. Jakarta: PT. Elex Media Komputindo

[2] Faas, R., Thompsons, J. R., Pienieszek, H. J. 2009. Pharmacokinetic comparison of orallydisintegrating metoclopramide with conventional metoclopramide tablet formulation in healthy volunteers, Aliment Pharmacol Theraphy, 30: hal 301-306.

[3] Ansel, H.C. 2017. Ansel's Pharmaceutical Dosage Forms And Drug Delivery Systems. Ninth Edition. Philadelphia.

[4] Hadisoewignyo L. and Fudholi A. 2013. Sediaan Solida. Pustaka Pelajar: Yogyakarta.

[5] Siregar, C.J.P., dan Wikarsa, S., 2010, Teknologi Farmasi Sediaan Tablet Dasar-Dasar Praktis, Penerbit Buku Kedokteran EGC, Jakarta.

[6] Solanki, H.K., Basuri T., Thakkar, J.H., and Patel, C.A., 2018. Recent Advences in Granulation Technology. International Journal of Pharmaceutical Sciences Review and Research, Vol. 5, Issue 3.

[7] Syamsuni, 2006, Farmasetika Dasar Dan Hitungan Farmasi, Penerbit Buku Kedokteran EGC, Jakarta.

[8] Kumar, D, D S Goswami, P Tomar, S Kaur. 2014. Formulation And Characterization Of Chewable Tablets Of Paracetamol And Metoclopramide Hydrochloride. Barnala: S. D. College of Pharmacy.

[9] Rowe, R.C. et Al. 2018.Handbook Of Pharmaceutical Excipients, 6thEd, The Pharmaceutical Press, London.

[10] Hartanto, Rudy. 2018. Modul Metodologi Penelitian. Semarang. Laboratorium Biometrika Fakultas Peternakan Universitas Diponegoro.

[11] Hadisoewignyo, Lannie dan Achmad Fudholi. 2018. Studi Pelepasan In Vitro Ibuprofen Dari Matrix Xanthan Gum Yang Dikombinasikan Dengan Suatu Crosslinking Agent. Yogyakarta. Fakultas Farmasi Universitas Gadjah Mada.

[12] Oka Sri Susanthi A.A, Setyawan Eka Indra, dan Dewantara Putra I G.N.A. 2017. Pengaruh Variasi Konsentrasi Magnesium Stearat Sebagai Bahan Pelicin Terhadap Sifat Fisik Tablet Vitamin E Untuk Anjing. Universitas Udayana.

[13] Padmadisastra, Yudi dan Drajad Priambodo. 2017. Formulasi Tablet Ekstrak Buah Cabe Jawa (Piper Retrofractum Vahl.) Dengan Metode Kempa Langsung. Sumedang. Jurusan Farmasi FMIPA Universitas Padjajaran.

[14] Ignatavicius, D. D., \& Workman, M. L. 2006. Medical-Surgical Nursing: Critical Thinking for Collaborative Care. (Edisi ke-5 St. Louis: Elsevier Inc). 
[15] Sheth, B.B., Bandelin F.J., Shangraw R.F. 2016. Compressed Tablet, in Lachman L., Lieberman H.A., Kanig J.L. (editor). Pharmaceutical Dosage Forms, Tablets, Volume I. New York: Marcel Dekker Inc. 